\title{
Sistem Cerdas Deteksi Sinyal Elektrokardiogram (EKG) untuk Klasifikasi Jantung Normal dan Abnormal Menggunakan Jaringan Syaraf Tiruan (JST)
}

\author{
Myza Rifali ${ }^{1}$, Dessy Irmawati ${ }^{2}$ \\ 1,2Program Studi Teknik Elektronika Fakultas Teknik Universitas Negeri Yogyakarta \\ E-mail: rifalimyza@gmail.com
}

\begin{abstract}
This article aims to describe the accuracy of signal processing using neural networks. The design of this final project hardware consists of Arduino Uno, AD8232 module and electrodes. ECG signals obtained from respondents were used as test data for normal ECG signals, while for abnormal class test data the data used were obtained from the research website, namely physionet with atrial fibrillation class. The design process in this system includes the process of data acquisition, training, feature extraction, testing and classification with artificial neural networks. Based on the results of the performance of this device to record ECG signals on respondents obtained normal ECG signals because the results of recorded ECG signals have a similarity in the PQRST wave with a predetermined target. This system can detect the classification of the heart by recognizing the statistical characteristics of the two signal classes and is trained using neural networks. Based on the testing process using an artificial neural network obtained an accuracy of $76.9 \%$.
\end{abstract}

Keywords: Electrocardiogram, Heart, AD8232 module, Arduino, Artificial Neural Network

\begin{abstract}
ABSTRAK
Artikel ini bertujuan untuk menggambarkan akurasi pemrosesan sinyal menggunakan jaringan saraf. Desain perangkat keras tugas akhir ini terdiri dari Arduino Uno, modul AD8232 dan elektroda. Sinyal EKG yang diperoleh dari responden digunakan sebagai data uji untuk sinyal EKG normal, sedangkan untuk data tes kelas abnormal, data yang digunakan diperoleh dari situs web penelitian, yaitu physionet dengan kelas fibrilasi atrium. Proses desain dalam sistem ini mencakup proses akuisisi data, pelatihan, ekstraksi fitur, pengujian dan klasifikasi dengan jaringan saraf tiruan. Berdasarkan hasil kinerja perangkat ini untuk merekam sinyal EKG pada responden diperoleh sinyal EKG normal karena hasil rekaman sinyal EKG memiliki kesamaan pada gelombang PQRST dengan target yang telah ditentukan. Sistem ini dapat mendeteksi klasifikasi jantung dengan mengenali karakteristik statistik dari dua kelas sinyal dan dilatih menggunakan jaringan saraf. Berdasarkan proses pengujian menggunakan jaringan saraf tiruan diperoleh akurasi $76,9 \%$.
\end{abstract}

Kata kunci: Elektrokardiogram,Jantung, modul AD8232,Arduino, Jaringan Syaraf Tiruan

\section{PENDAHULUAN}

Sejak tahun 1996 penyakit atau kelainan pada jantung merupakan salah satu penyebab kematian yang utama di Indonesia [1]. Tidak hanya di Indonesia, di Hongkong penyakit Jantung telah menjadi penyakit pembunuh kedua setelah kanker [2]. Di Korea Selatan, penyakit kardiovaskular, termasuk penyakit jantung (mis., Infark miokard, angina, dan gagal jantung) dan penyakit serebrovaskular adalah penyebab utama kematian. Penyakit kardiovaskular menyebabkan 1 dari setiap 5 kematian [3]. Banyaknya jumlah kematian akibat penyakit jantung disebabkan oleh minimnya kesadaran diri pada setiap orang bahwa jantung merupakan organ yang vital dan penting yang harus dipantau secara berkala. Sehingga kerap ketika seseorang merasa sedang dalam kondisi yang kurang sehat, orang-orang masih enggan untuk memeriksakan kondisinya dan menganggap bahwa yang dirasakan oleh tubuhnya adalah hanya lelah semata sehingga tidak memikirkan bagaimana kondisi tubuh bahkan jantungnya. 
Saat ini metode yang paling umum untuk mendeteksi penyakit atau kelainan pada jantung adalah menggunakan Elektrokardiogram (EKG). EKG merupakan suatu alat yang digunakan untuk merekam aktivitas listrik pada jantung dengan memanfaatkan elektroda yang ditempelkan pada bagian-bagian tubuh [4]. Biasanya sinyal EKG yang dihasilkan dari elektroda ditampilkan pada sebuah layar osiloskop. Namun, seiring perkembangan zaman banyak cara untuk mengetahui pengenalan sinyal EKG. Salah satunya yaitu dengan menampilkan sinyal EKG tersebut pada monitor PC/Laptop. Sehingga, pengenalan sinyal EKG dapat dilakukan lebih mudah dan juga membantu para ahli ataupun peneliti untuk mengolah lebih lanjut data sinyal EKG tersebut.

Sistem Cerdas merupakan bagian dari bidang Ilmu Komputer/Informatika dan Rekayasa Cerdas untuk pengembangan berbagai metode bekemampuan tinggi yang diilhami oleh fenomena alam untuk menyelesaikan berbagai masalah kompleks di dunia nyata.Masalahmasalah kompleks tersebut juga bisa berkaitan dengan pengolahan big data dan perancangan embedded system. Sebuah sistem cerdas digunakan untuk mampu menghasilkan sistem dan perangkat lunak berbasis algoritma cerdas, baik inter maupun multi disipliner dengan kemampuan analisis dan teknis sehinggga menghasilkan karya inovatif dan teruji [5].

EKG adalah suatu alat diagnostik yang digunakan untuk mendeteksi aktivitas kelistrikan pada jantung berupa grafik yang merekam perubahan listrik pada jantung yang kemudian dihubungkan dengan waktu. Pada gelombang sinyal EKG nantinya akan terlihat gelombang yang biasa disebut sebagai gelombang $\mathrm{P}, \mathrm{QRS}$ dan $\mathrm{T}$ yang dapat dilihat pada Gambar 1. Fungsi dari EKG antara lain yaitu untuk mengetahui jika terjadi kelainan irama pada jantung, mengetahui kelainan otot jantung, menilai fungsi jantung, memperkirakan adanya pembesaran jantung/hipertopi atrium dan ventrikel, dan juga pengaruh efek obat-obat jantung.

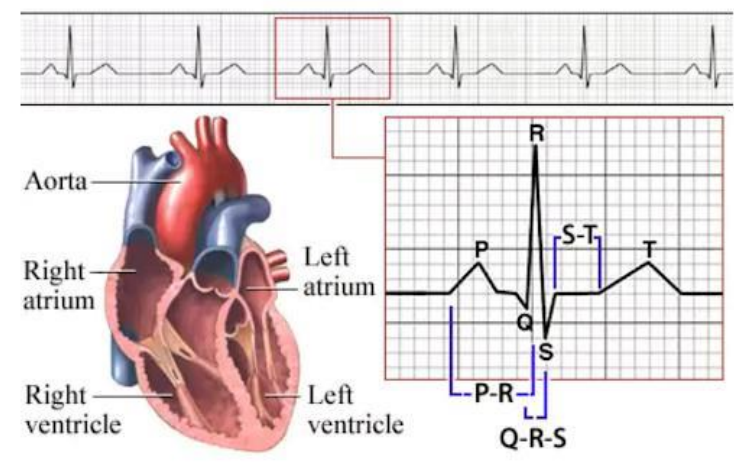

Gambar 1. Sinyal Jantung pada EKG [6]

Dalam keadaan normal impuls untuk kontraksi jantung berasal dari nodus SA dengan melewati serabut-serabut otot atrium impuls diteruskan ke nodus AV, dan seterusnya melalui berkas His $\rightarrow$ cabang His kiri dan kanan $\rightarrow$ jaringan Purkinye $\rightarrow$ akhirnya ke serabut otot ventrikel. Disini nodus SA menjadi pacemaker utama dan pacemaker lain yang terletak lebih rendah tidak berfungsi. Apabila nodus SA terganggu maka fungsi sebagai pacemaker digantikan oleh pacemaker yang lain. Irama jantung normal demikian dinamakan irama sinus ritmis yaitu iramanya teratur, dan tiap gelombang $\mathrm{P}$ diikuti oleh kompleks QRS. Irama sinus merupakan irama yang normal dari jantung dan nodus SA sebagai pacemaker.

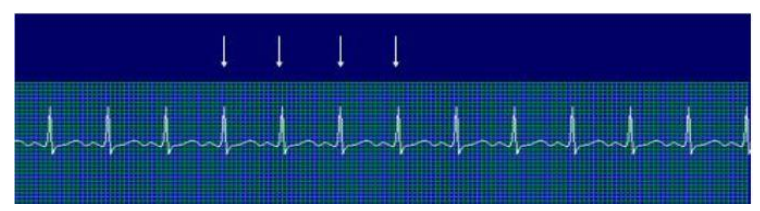

Gambar 2. Sinyal EKG Jantung Normal [7]

Berdasarkan Gambar 2 irama sinus normal memilki ciri antara lain, morfologi gelombang $\mathrm{P}$ normal, tiap gelombang $\mathrm{P}$ diikuti satu kompleks QRS, Gelombang P defleksi positif disadapan I, Gelombang P dan kompleks QRS defleksi negatif di lead avR. Fibrilasi atrium merupakan ritme denyut jantung abnormal pada jantung yang ditandai dengan aktivitas atrium yang cepat dan tidak efektif serta kontraksi ventrikuler yang tidak teratur. Berdasarkan Gambar 3 sinyal EKG Atrial Fibrilasi memilki ciri antara lain, ciri khas dari 
$\mathrm{AF}$ adalah tidak adanya gelombang $\mathrm{P}$ dan iramanya ireguler, morfologi gelombang $\mathrm{P}$ berupa fibrilasi

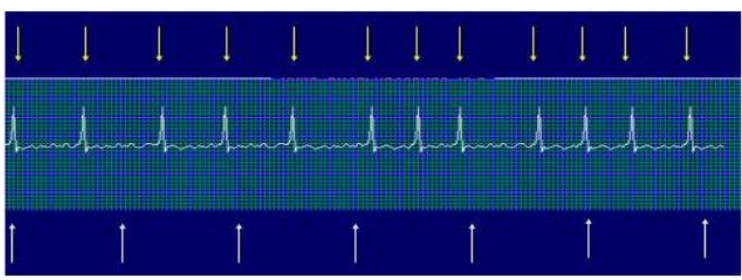

Gambar 3. Sinyal EKG Jantung Abnormal Atrial Fibrilasi [7]

Jaringan saraf tiruan merupakan salah satu bagian dari kecerdasan buatan (Artificial Intelegence). Jaringan saraf tiruan dapat dikatakan sebagai kecerdasan buatan karena dapat mensimulasikan proses pembelajaran pada otak manusia yang disusun dengan sel-sel atau neuron buatan. Istilah buatan ini diimplementasikan dengan menggunakan program komputer yang dapat menyelesaikan sebuah permasalahan dan juga sejumlah proses perhitungan selama pembelajaran. Terdapat banyak jenis metode pada jaringan saraf tiruan, salah satunya yaitu backpropagation [8]. Backpropagation merupakan sebuah algoritma pembelajaran yang terawasi dengan menggunakan banyak lapisan untuk mengubah bobot-bobot yang ada dengan neuron-neuron yang terdapat lapisan tersebunyinya. Algoritma pembelajaran dari backpropagation yaitu untuk memperkecil tingkat error dengan menyesuaikan bobotnya berdasarkan output dan target yang diinginkan.

\section{METODE}

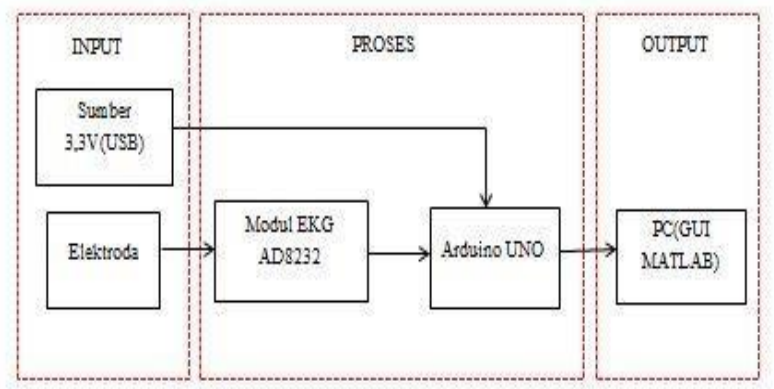

Gambar 4. Blok Diagram Sistem
Metode yang dilakukan dalam penelitian ini terdiri dari dua tahap yaitu blok diagram dan perancangan sistem. Gambar 4 merupakan bagian blok diagram.rangkaian keseluruhan proses yang diaplikasikan pada sistem kendali cerdas deteksi sinyal EKG untuk klasifikasi jantung normal dan abnormal menggunakan jaringan saraf tiruan yang terdiri dari: (1) Elektroda memiliki fungsi sebagai inputan yang akan memberikan tegangan dari jantung yang kemudian diolah sinyal tersebut didalam modul ad8232. (2) Catu daya memiliki fungsi sebagai sumber daya maskan untuk supply arduino uno dan modul AD8232. (3) Arduino Uno dan modul AD8232 berfungsi sebagai pengolah dan pengkonversi sinyal (4) GUI Matlab berfungsi sebagai sistem untuk menampilkan hasil gelombang sinyal EKG dan klasifikasi jantung normal/abnormal.

Perancangan Sistem Cerdas Deteksi Sinyal Elektrokardiogram ini terdiri dari perancangan hardware, software dan desain keseluruhan. Hardware terdiri atas: (1) Rangkaian arduino uno yang berfungsi sebagai kendali utama yang menjalankan rangkaian yang digunakan; dan (2) Rangkaian modul AD8232 yang berfungsi sebagai pemroses input tegangan yang diperoleh dari sadapan elektroda, untuk diproses agar mendapatkan sinyal EKG. Proyek ini menggunakan elektroda yang akan dipasangkan pada modul AD8232 dengan bentuk jack 3,5mm. Software terdiri atas: (1) Perancangan GUI matlab. Aplikasi yang digunakan pada sistem ini yaitu menggunakan GUI, yang masih merupakan bagian dari matlab namun GUI ini berfungsi untuk dapat menampilkan hasil dari sistem cerdas pengolahan sinyal EKG untuk mendeteksi jantung normal dan abnormal dengan jaringan saraf tiruan; dan (2) Perancangan arsitektur JST yang terdiri atas (a) Pelatihan, pembuatan program pada matab dimulai dengan membuat program pelatihan yang terdiri dari folder data latih. Folder data latih merupakan folder yang berisi data sinyal EKG dari masing-masing kelas berjumlah 82 sinyal yang diperoleh dari physionet. Sinyal tersebut kemudian dilakukan 
pelatihan dengan menggunakan jaringan saraf tiruan agar dapat dikenali cirinya; dan (b) pengujian, yaitu dengan membuat program pengujian yang terdiri dari folder data uji. Folder data uji merupakan folder yang berisi data sinyal EKG berjumlah 26 sinyal dari kedua kelas. Sinyal tersebut yang kemudian akan dipilih secara acak dan dapat diklasifikasikan dengan menggunakan aplikasi GUI. Desain keseluruhan dapat dilihat pada Gambar 5.

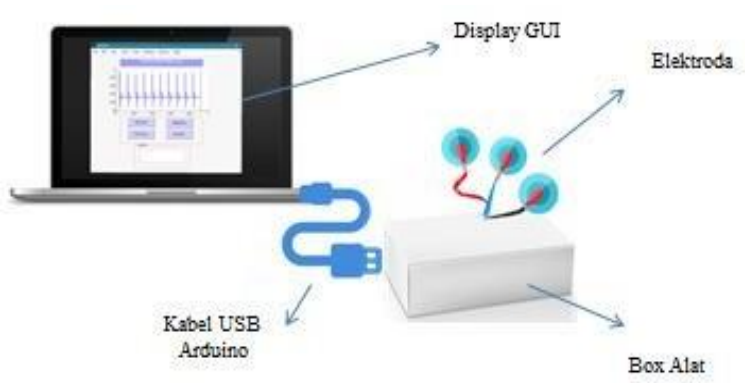

Gambar 5. Desain alat keseluruhan

\section{HASIL DAN PEMBAHASAN}

Tabel 1. Pengujian pada serial plotter arduino

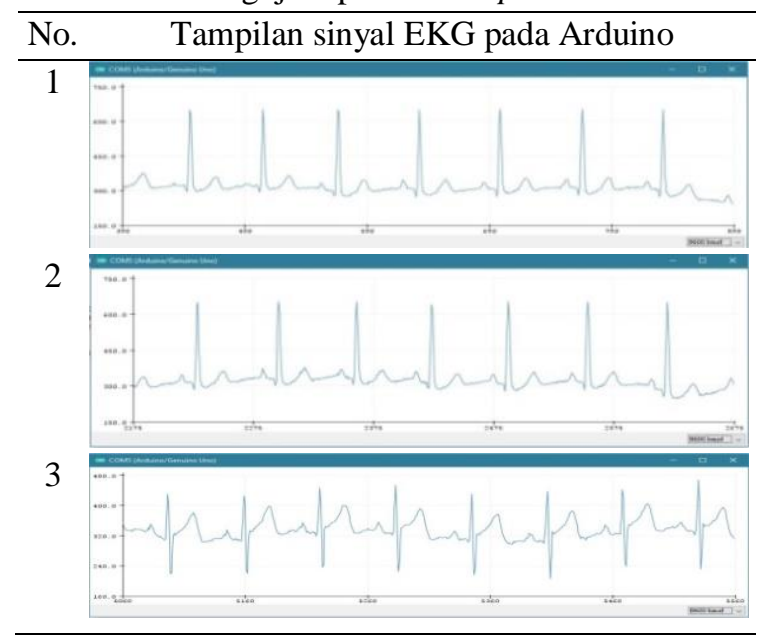

Pengujian alat dilakukan dilakukan untuk mendapatkan data penelitian. Pengujian alat dan sistem ini dilakukan dengan empat pengujian, yaitu pengujian pada serial plotter arduino, pengujian fungsi tombol-tombol GUI, pengujian display sinyal EKG pada aplikasi dan pengujian unjuk kerja secara keseluruhan. Tabel 1 merupakan pengujian pada serial plotter arduino. Tabel 1 ini berisikan display grafik sinyal EKG yang didapat dari pemasangan elektroda pada responden dengan kondisi normal. Pengujian alat ini ditampilkan pada serial plotter di Arduino, pengujian ini dilakukan untuk dapat melihat bahwa rangkaian dari arduino dan modul dapat bekerja dengan baik karena dapat menampilkan sinyal EKG dari responden. Tabel 2 menyajikan pengujian fungsi tombol pada GUI.

Tabel 2. Pengujian tombol yang digunakan pada display home GUI

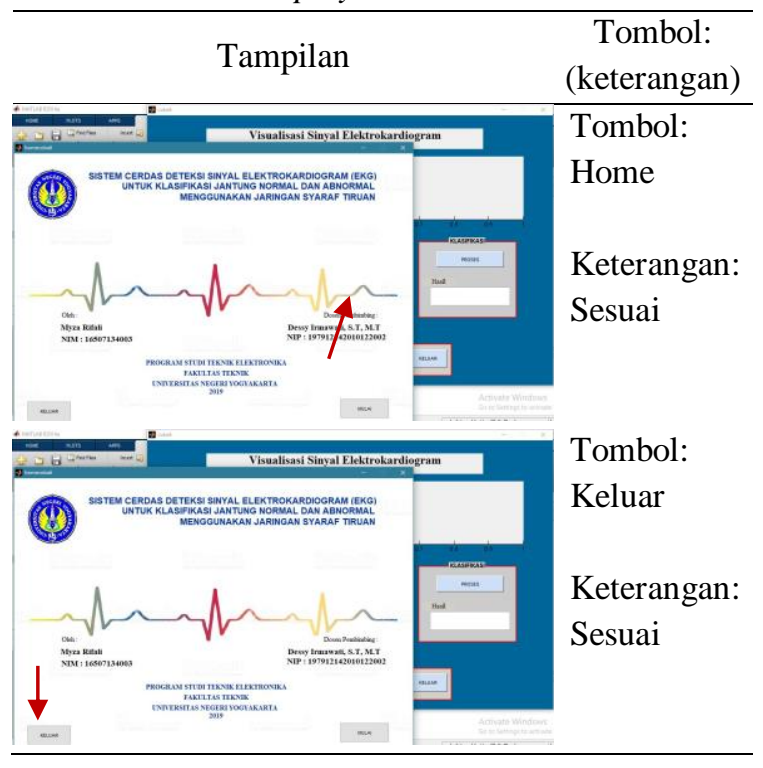

Tabel 2 berisikan pengujian tombol yang berada pada home GUI, terdapat dua tombol yang tersedia yaitu tombol Mulai dan tombol Keluar. Tombol mulai dapat digunakan dengan baik karena bisa menampilkan ke tampilan selanjutya, sementara pada tombol keluar juga dapat digunakan dengan baik karena bisa mengeluarkan aplikasi jika sudah tidak diinginkan.

Tabel 3 dilakukan pengujian fungsi tombol pada panel input sinyal, terdapat 2 tombol yang tersedia pada panel ini yaitu tombol rekam dan tombol simpan. Tombol rekam berfungsi untuk menghubungkan koneksi antara alat dengan sistem, yaitu antara arduino dan juga matlab untuk dapat merekam sinyal EKG pada tubuh. Sementara, tombol simpan digunakan untuk menyimpan hasil sinyal EKG yang direkam melalui alat. Kedua tombol ini dapat digunakan dengan baik karena berjalan sesuai dengan fungsinya. 
Tabel 3. Pengujian tombol yang digunakan pada panel input sinyal.

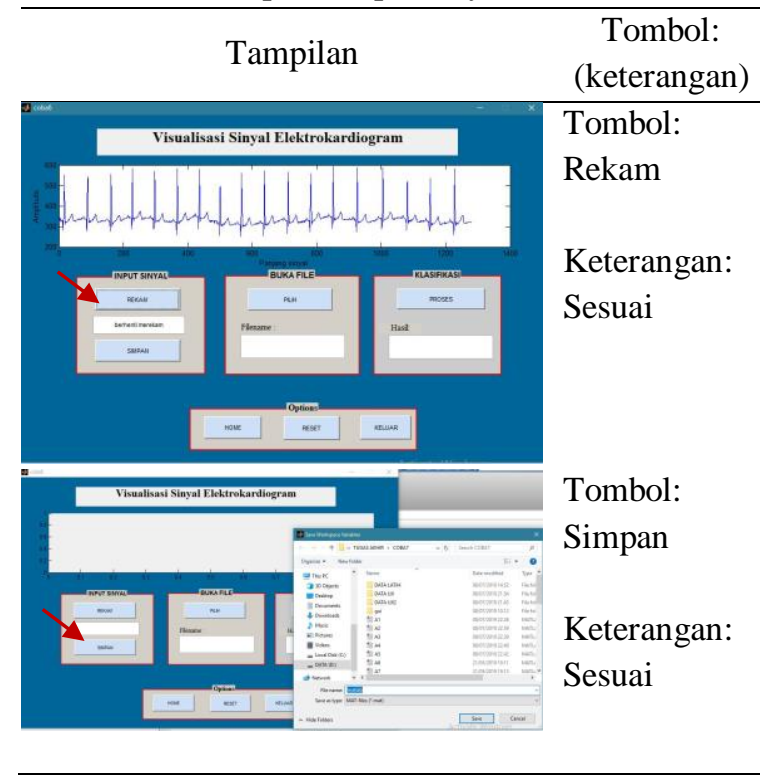

Pada Tabel 4 dilakukan pengujian tombol pada panel buka file, terdapat satu tombol yaitu tombol pilih yang digunakan untuk membuka folder yang berisi file-file sinyal EKG yang telah direkam sebelumnya, maupun yang telah ada kemudian memilihnya, sehingga sinyal EKG dapat ditampilkan di grafik diikuti dengan nama file yang dibuka pada kolom filename. Tombol pilih ini dapat digunakan dengan baik sesuai dengan fungsinya.

Tabel 4. Pengujian tombol yang digunakan pada panel buka file

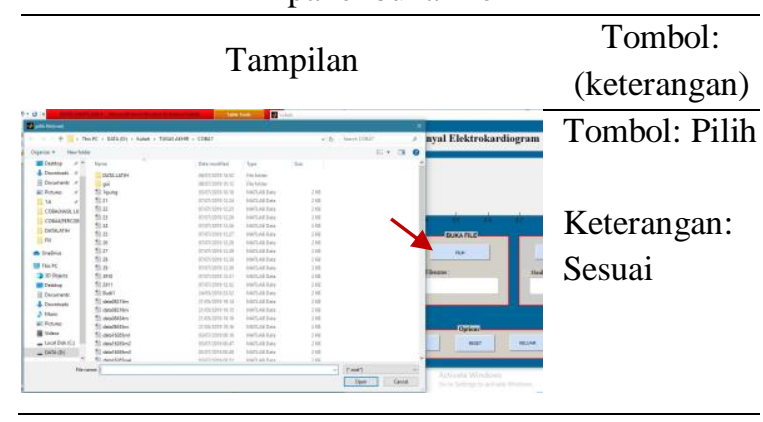

Tabel 5 berisikan pengujian pada panel klasifikasi. Terdapat satu tombol yang tersedia yaitu tombol proses yang digunakan untuk mengolah sinyal EKG yang telah dipilih untuk diketahui cirinya dan dapat diklasifikasikan sesuai dengan kelasnya, hasil dari klasifikasi tersebut dapat dilihat pada kolom hasil. Tombol ini dapat digunakan dengan baik sesuai dengan fungsinya.

Tabel 5. Pengujian tombol yang digunakan pada panel klasifikasi

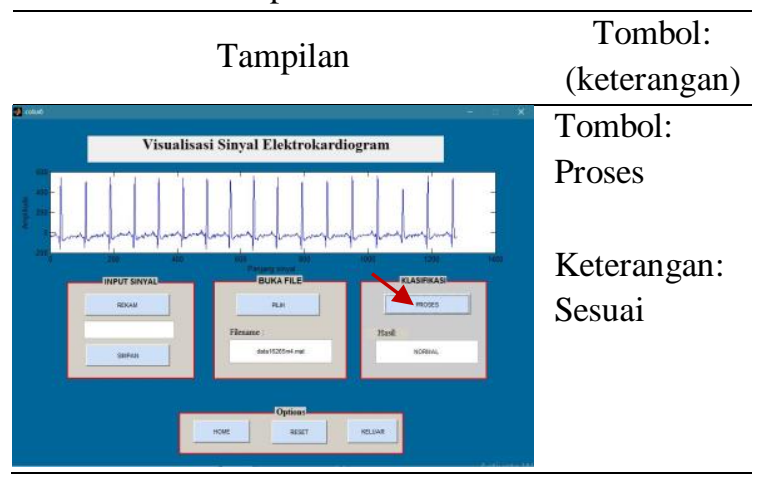

Tabel 6. Pengujian tombol yang digunakan pada panel options

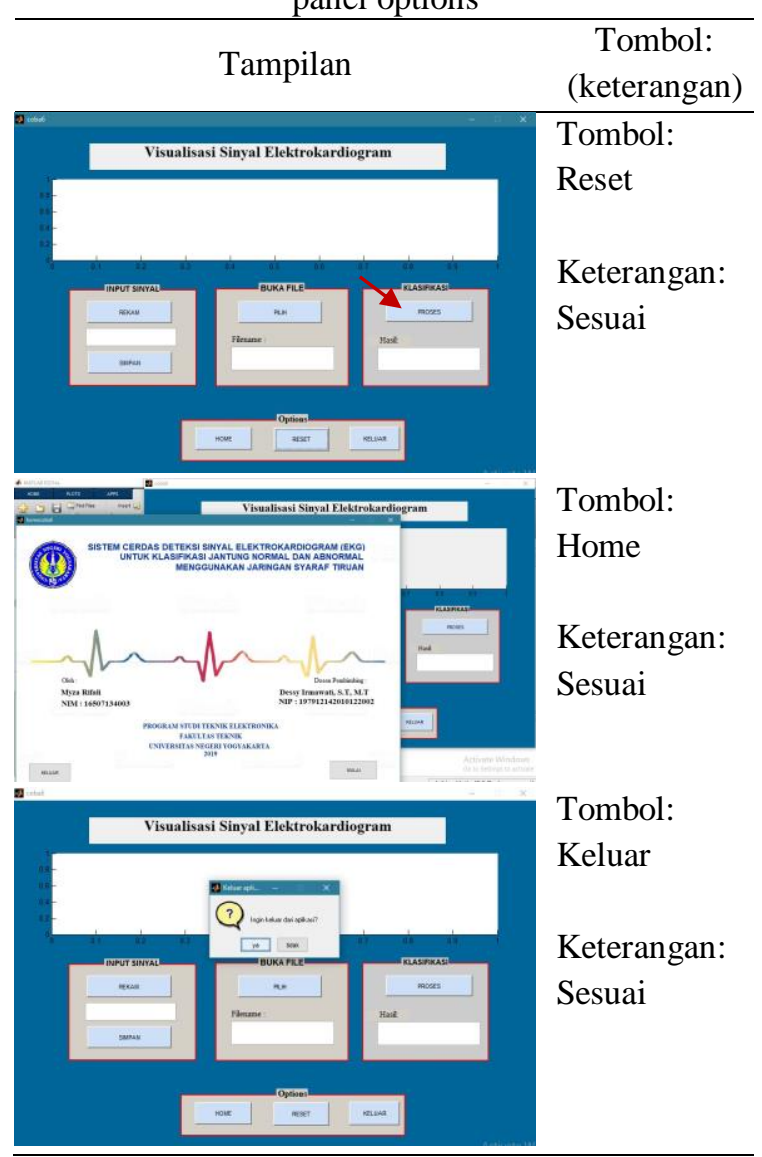

Tabel 6 merupakan pengujian tombol pada panel options, terdapat 3 tombol yang tersedia pada panel ini yaitu tombol reset, tombol home dan tombol keluar. Tombol reset digunakan untuk menghapus data-data sinyal yang telah terbuka pada sistem, kemudian mengembalikan sistem seperti keadaan yang 
belum pernah digunakan untuk dapat membuka file yang setelahnya. Tombol home digunakan untuk kembali kehalaman awal sistem, sementara tombol keluar digunakan untuk keluar atau menutup aplikasi. Ketiga tombol tersebut dapat digunakan dengan baik dan berjalan sesuai dengan fungsinya.

Tabel 7. Pengujian display sinyal EKG normal di aplikasi GUI matlab

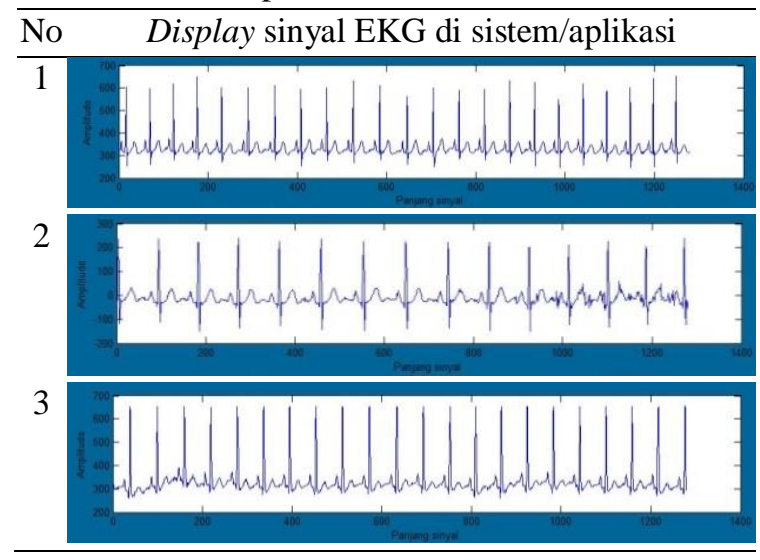

Tabel 7 merupakan pengujian display sinyal EKG pada aplikasi GUI matlab, yang digunakan sebagai interface pada matlab untuk dapat melihat sinyal EKG yang diperoleh dari hasil rekam pada responden. Berdasarkan beberapa data yang diambil dapat dikatakan bahwa grafik sinyal EKG yang ditampilkan hampir menyerupai sinyal EKG yang normal, karena dapat terlihat gelombang PQRST pada sinyal EKG tersebut. Kemudian sinyal-sinyal tersebut dapat terlihat berbeda karena dapat disebabkan oleh posisi penempatan elektroda yang kurang baik, ataupun saat pengambilan terjadi gerakan tidak disadari/tidak disengaja yang dapat mengganggu hasil dari sinyal EKG.

Tabel 8 merupakan pengujian display sinyal EKG pada aplikasi GUI matlab, yang digunakan sebagai interface pada matlab untuk dapat melihat sinyal EKG yang diperoleh dari hasil web penelitian physionet kelas abnormal. Berdasarkan beberapa data yang diambil dapat dikatakan bahwa grafik sinyal EKG yang ditampilkan tidak menyerupai sinyal EKG yang normal, karena tidak dapat terlihatnya gelombang $\mathrm{P}$ yang mana sesuai dengan ciri pada karakteristik sinyal EKG Atrial Fibrilasi.
Tabel 8. Pengujian display sinyal EKG abnormal di aplikasi GUI matlab

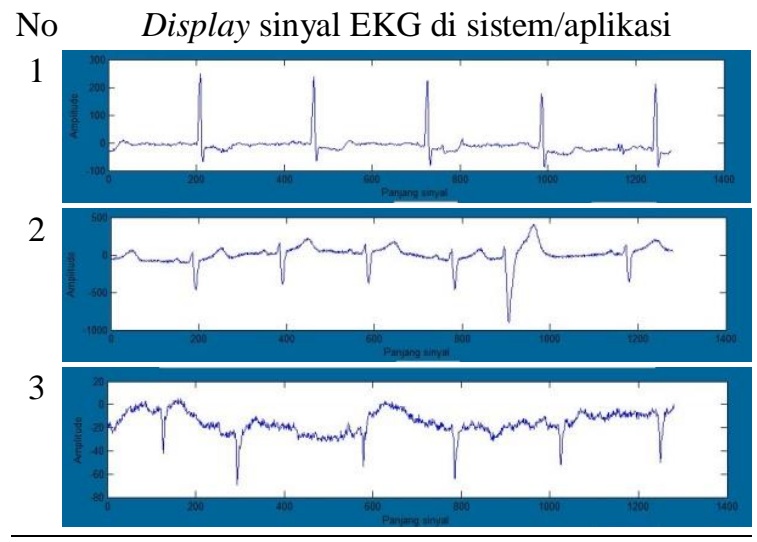

Tabel 9. Pengujian hasil klasifikasi jantung normal dan abnormal

\begin{tabular}{ccccc}
\hline No & Data & Kelas Asli & $\begin{array}{c}\text { Hasil } \\
\text { Klasifikasi }\end{array}$ & Ket \\
\hline 1 & A1 & Abnormal & Abnormal & Benar \\
2 & A2 & Abnormal & Abnormal & Benar \\
3 & A3 & Abnormal & Abnormal & Benar \\
4 & A4 & Abnormal & Abnormal & Benar \\
5 & A5 & Abnormal & Normal & Salah \\
6 & A6 & Abnormal & Abnormal & Benar \\
7 & A7 & Abnormal & Abnormal & Benar \\
8 & A8 & Abnormal & Abnormal & Benar \\
9 & A9 & Abnormal & Abnormal & Benar \\
10 & A10 & Abnormal & Abnormal & Benar \\
11 & A11 & Abnormal & Abnormal & Benar \\
12 & A12 & Abnormal & Abnormal & Benar \\
13 & A13 & Abnormal & Normal & Salah \\
14 & N1 & Normal & Normal & Benar \\
15 & N2 & Normal & Normal & Benar \\
16 & N3 & Normal & Abnormal & Salah \\
17 & N4 & Normal & Abnormal & Salah \\
18 & N5 & Normal & Normal & Benar \\
19 & N6 & Normal & Abnormal & Salah \\
20 & N7 & Normal & Abnormal & Salah \\
21 & N8 & Normal & Normal & Benar \\
22 & N9 & Normal & Normal & Benar \\
23 & N10 & Normal & Normal & Benar \\
24 & N11 & Normal & Normal & Benar \\
25 & N12 & Normal & Normal & Benar \\
26 & N13 & Normal & Normal & Benar \\
\hline & & & &
\end{tabular}

Tabel 9 merupakan pengujian unjuk kerja sistem secara keseluruhan, yakni untuk mengklasifikan jantung normal dan abnormal. Berdasarkan tabel diatas dapat dilihat, bahwa data yang dilakukan sebagai data pengujian sejumlah 26 data yang terdiri dari data normal sebanyak 13 sinyal EKG dan dari data abnormal sebanyak 13 sinyal EKG. Sejumlah 6 buah 
sinyal EKG masih salah dideteksi dengan benar oleh sistem yang ditunjukan dengan label kuning. Jadi berdasarkan tabel tersebut diperoleh akurasi pengujian yaitu 76,92\%.

\section{SIMPULAN}

Berdasarkan hasil pengujian yang telah dilakukan pada sistem cerdas deteksi sinyal elektrokardiogram untuk klasifikasi jantung normal dan abnormal menggunakan jaringan syaraf tiruan, maka dapat disimpulkan: (1) sistem cerdas pengolahan sinyal untuk dapat mendeteksi sinyal EKG normal dan abnormal terealisasi dengan menggunakan modul AD8232 dan Arduino Uno dalam pengambilan data sinyal EKG normal; dan (2) Cara kerja dari sistem yang menggunakan jaringan syaraf tiruan sudah berfungsi dengan baik. Jaringan syaraf tiruan yang digunakan pada pelatihan dan pengujian mampu mengenali ciri yang diberikan dan $76 \%$ berhasil mengklasifikasikan sinyal sesuai dengan kelasnya.

Sistem cerdas deteksi sinyal elektrokardiogram untuk klasifikasi jantung normal dan abnormal menggunakan jaringan syaraf tiruan, masih memiliki keterbatasan dalam sistem kerjanya, antara lain: (1) Masih belum adanya data sinyal EKG abnormal pada responden yang direkam menggunakan alat ini karena sulitnya untuk mendapatkan responden dengan sinyal EKG abnormal; (2) Belum dilakukannya validasi data dengan para ahli sehingga data yang digunakan untuk pelatihan masih mengacu pada web penelitian physionet; (3) Sistem ini belum berdiri sendiri menjadi sebuah aplikasi. Beberapa saran untuk penyempurnaan perangkat ini antara lain sebagai berikut: (1) modul EKG AD8232 dapat diganti dengan modul EKG yang memiiki spesifikasi lebih tinggi; (2) merancang kembali arsitektur jaringan yang tepat pada jaringan syaraf tiruan dengan menambah jumlah ekstraksi ciri dan hidden layer yang digunakan agar hasil akurasi pengenalan pola dapat lebih maksimal; dan (3) menjadikan system cerdas ini menjadi sebuah aplikasi yang dapat berdiri sendiri.

\section{DAFTAR PUSTAKA}

[1] F. Zennifa and H. K. Fitrilina, "Prototipe Alat Deteksi Dini dan mandiri penyakit Jantung Menggunakan Sistem Pakar VCIRS, Arduino dan Handphone Android," Universitas Andalas, 2013.

[2] H. Author, "Coronary Heart Disease/ Indonesian (Penyakit Jantung Koroner)," Smart Patient, 2018. [Online]. Available: https://www21.ha.org.hk/smartpatient/EM/Medi aLibraries/EM/EMMedia/Coronary-HeartDisease-Indonesian-201801.pdf?ext=.pdf. [Accessed: 10-Nov-2018].

[3] H.-Y. Shin, J.-Y. Lee, J. Song, S. Lee, J. Lee, B. Lim, H. Kim, and S. Huh, "Cause-of-death statistics in the Republic of Korea, 2014," $J$. Korean Med. Assoc., vol. 59, no. 3, pp. 221-232, 2016.

[4] J. Halomoan, "Analisa Sinyal EKG dengan Metoda HRV (Heart Rate Variability)pada Domain WaktuAktivitas Berdiri dan Terlentang," in Seminar Nasional Aplikasi Teknologi Informasi (SNATI), 2013, pp. 29-35.

[5] M. N. Sidqi, "Sistem Cerdas Deteksi Suara Untuk Pengklasifikasian Penyakit Jantung Menggunakan Jaringan Saraf Tiruan," UNY, 2018.

[6] B. H. Centre, "Electrocardiography (EKG)," Bunda Heart Centre, 2019. [Online]. Available: http://www.bundaheartcentre.com/wpcontent/uploads/2015/04/ECG_hart-normal.jpg.

[7] H. Sulastomo, R. Kusumawati, Y. H. Suselo, N. Purwaningtyas, D. Indarto, S. A. Jusup, and R. Myrtha, Buku Manual Keterampilan Klinis Interpretasi Pemeriksaan Elektrokardiografi (EKG). Surakarta: Fakultas Kedokteran Universitas Sebelas Maret Surakarta, 2019.

[8] A. Hermawan, Jaringan Syaraf Tiruan Teori dan Aplikasi. Yogyakarta: Penerbit Andi, 2006. 